Dini, D. \& Liu, L. (2017). Intrinsic Motivation Factors in Gamified Photography Learning: Direct and Indirect Effects. Journal of Educational Technology Development and Exchange, 10(2), 1-24.

\title{
Intrinsic Motivation Factors in Gamified Photography Learning: Direct and Indirect Effects
}

\author{
Domenic Dini \\ University of Nevada, Reno, USA \\ Leping Liu \\ University of Nevada, Reno, USA
}

\begin{abstract}
To help students with motivation to learn, gamification has been explored as a method of delivering content to students in an engaging and motivating way. This study explored the motivation components in gamified design that linked to learning outcomes in a gamified photography curriculum. Six intrinsically motivating factors (challenge, curiosity, control, cooperation, competition, and recognition) were carefully integrated into the game experience design. Participant test scores and survey data were used to develop a maximum likelihood structural equation model. The model showed that among the six intrinsic motivation factors curiosity and control were directly linked to learning outcomes while challenge had an indirect link to learning outcomes. These findings suggest that these three items need to be carefully integrated into gamified lesson design to promote engagement and learning.
\end{abstract}

Keywords: gamification, photography learning, intrinsic and extrinsic motivation

\section{Introduction}

Due to the changing nature of the global economic environment, the educational landscape has been going through its own transformation so that future workers are better equipped to be successful in new and emerging careers. The transformation is attributed to changes in job skills that involve higher-order thinking skills, which requires educators to prepare students to be competitive in a global work environment (Boyles, 2012). The shift in requirements for workers has caused the educational landscape to change from a model where information is absorbed through teacher-centered interactions to one where learners are expected to demonstrate competencies in skills needed in the workplace, such as thinking, problem solving, collaboration, and communication (Wagner, 2014; Partnership for $21^{\text {st }}$ Century Skills, 2015). These skills have become necessary for future workers to develop as computers have the capacity to perform repetitive tasks accurately, replacing human workers in the process (Borenstein, 2011). 
One common issue in preparing learners with $21^{\text {st }}$ century skills to be job-ready is that teachers are having difficulties motivating students to learn. This may be related to the use of longstanding teacher-centered methods, such as large-group lecture, where students are passively taught (Kapp, 2012a). Lack of active engagement and peer interactions often lead to an overreliance on extrinsic motivators such as grades, credits, and diplomas, and creates learners who are disinterested in learning ((Banfield \& Wilkerson, 2014; Berkling \& Thomas, 2013; Lee \& Hammer, 2011; Mozelius, 2014). To help students become more motivated to learn, gamification has been explored to provide students with engaging learning environments. Gamification is defined as "the use of game design elements in non-game contexts" (Deterding, Dixon, Khaled, \& Nacke, 2011, p. 10). Due to the universal nature of games and their natural motivating power, it is expected that integrating gamification principles into learning experiences would improve students' motivation to learn (Dicheva et al., 2015).

This study aimed to explore the effects of the intrinsically motivating factors on students' gamified learning outcomes. In the study, middle school students took part in a gamified curriculum on photography skills and were tested on their knowledge after the game. Students were surveyed about their learning experience on six motivational factors (challenge, curiosity, control, cooperation, competition, and recognition) proposed by Malone and Lepper (1987). The tests and survey data were used to develop a structural equation model (SEM) that demonstrates the effects examined through the research question of this study:

Which motivational variables (challenge, curiosity, control, cooperation, competition, and recognition) have a direct or indirect effect on middle school students' gamified photography skills learning?

\section{Literature Review}

In an effort to improve education and engage more students in learning, gamification has been explored as a mechanism to create a unique learning experience. The aim of gamified design is to create tasks that require a combination of intrinsic and extrinsic motivation to complete and to use game elements to entice individuals to make thoughtful choices (Morford et al., 2014).

\subsection{Intrinsic and Extrinsic Motivation in Education}

Intrinsic motivation and extrinsic motivation are different based upon where the motivation to complete a task comes from. When a person has intrinsic motivation, they participate in an activity because they gain satisfaction from the task (Banfield \& Wilkerson, 2014). These individuals may seek out stronger challenges and develop more knowledge and skills due to self-motivation (Ryan \& Deci, 2000). Individuals who are extrinsically motivated perform a task because of some external reward earned by completing the task, such as money, grades, or other tangible reinforcements (Ryan \& Deci, 2000).

In the educational realm, educators hope that students are intrinsically motivated to learn and find internal value and interest in what they are learning. However, an overreliance on extrinsic motivators, such as food, grades, and tangible reinforcements, may have a negative effect on intrinsic motivation and cause students to find less value in learning new material (Ryan \& Deci, 2000). Intrinsically motivated students have a variety of advantages over externally motivated peers because they find the tasks enjoyable and are more likely to pursue academic tasks on their 
own without force (Lei, 2010). These students want to be educated because they find value in learning and collaborating with like-minded peers (Ryan \& Deci, 2010). Conversely, students with higher external motivation than internal motivation may show less interest in learning tasks, blame their teachers for poor performance, and refuse to complete learning tasks if there is no incentive to do so (Lei, 2010; Ryan \& Deci, 2000).

Extrinsically motivated students are at risk in the classroom because they may tend to have lower grades and have poor relationships with classmates and peers (Vecchione, Alessandri, \& Marsicano, 2014). Even if an extrinsically motivated student is capable of completing a learning task, they may refuse to do so unless there is some incentive to complete the task (Lei, 2010). In short, extrinsically motivated students may miss out on many learning opportunities simply because they choose not to take part in them and need to be incentivized to do so.

\subsection{Gamification}

The term gamification is relatively new, but the concepts behind gamification have existed throughout history. For example, badges earned through promotions in the military can be traced back to ancient Rome, while merit badges in the Boy Scouts of America have been used to show distinction among troop members (Antin \& Churchill, 2011; Dicheva et al., 2015). The term gamification was introduced in a conference in the early 2000's and slowly grew in popularity as a way to promote businesses and their products (Groh, 2012). Using a gamified design, games were developed that could motivate and influence behavior and help promote lifestyle changes for individuals who needed a motivational tool (Lee \& Hammer, 2011). Games have been developed to encourage healthy lifestyle choices, including monitoring household energy use, exercise, and completion of everyday tasks.

Due to the success found from gamified business applications and the motivational power of games, gamification was introduced to the educational realm for research and application. Gamification is defined as "the use of game design elements in non-game contexts" (Deterding, et al., 2011, p. 10). This definition makes gamification different from other forms of game-based learning because it does not require teachers to incorporate all of the design principles used to make fullfledged games. A teacher designing a gamified curriculum can select what components best fit her lesson design and leave out those that do not. Using this definition as the basis for gamified design, it is possible to create learning experiences for classroom use where the goal is learning new content in a fun and engaging way. Students who choose not to learn when traditional teaching methods are used may become engaged in learning content both consciously and subconsciously when games are the conduit for learning (Kapp, 2012a).

\subsection{Potential to Improve Motivation with Gamification}

To help students become more intrinsically motivated to learn new material, instructors are tasked with helping students to find internal value in their learning while minimizing external incentives (Lei, 2010). One method of developing intrinsically motivated students is to develop gamified instruction where students learn new material while playing games.

Gamification has the potential to increase engagement in learning due to the natural human interest in playing games, which can lead to increased motivation to acquire and 
improve skills (Apostol, Zaharescu, \& Alexe, 2013; Barata et al., 2015; Bíró, 2013; Measles and Abu-Dawood, 2015). The use of games creates moments where learners reflect on prior performance and adjust their play style so that they can improve their standing compared to other players. To remain competitive in a game, students must stretch their limits and develop more knowledge and skills so that they are better equipped to succeed compared to their peers (Apostol et al., 2013). Gamified learning also has the potential for students to create a social environment where they learn more about their peers and develop a shared knowledge bank (Barata et al., 2015).

Gamification also has the potential to create motivation and engagement in students, especially in those who are generally extrinsically motivated, because players receive unexpected rewards for "winning" the game as opposed to earning rewards simply by being in the classroom (Deci, Ryan, \& Koester, 1999). Gamified learning systems rely on both intrinsic and extrinsic motivation (Lamprinou \& Paraskeva, 2015), but the hope is that integrating game elements make students more intrinsically motivated because they have autonomy in their learning and can make choices as to how they learn new information (Ryan \& Deci, 2000). Using gamification, educators have the opportunity to help students find value in their learning and seek out more knowledge on their own. By doing so, it is possible for students to become more intrinsically motivated to learn and rely less on external factors to drive them.

\subsection{Features of Gamification}

Due to the nature of games and the way they invite individuals to interact with them, games can naturally intrinsically motivate users to keep playing (Measles \& Abu-Dawood, 2015). Games also usually provide an extrinsic reward, such as tokens or ranking, to tempt participants to keep playing and improving their status compared to other players. When designing a gamified experience, it is important to carefully select game elements that have a balance of external and internal motivators so that interest is held for the duration of the experience (Lamprinou \& Paraskeva, 2015). These game elements should also be age-appropriate and mesh well with the content they are learning (Glover, 2013). Gamified curriculum developers also cannot assume that gamifying learning experiences will automatically engage all learners (de-Marcos, Domínguez, Saenz-deNavarrete, \& Pagés, 2014). Doing so may cause learners to have a negative experience and disengage from the game and the intended learning outcomes. There are many things that need to be considered in order to develop an engaging, meaningful gamified experience for classroom use.

Along with rules, structure, and other factors that make the game enjoyable (Cronk, 2012; Kim, 2015; McGonigal, 2011), Kapp (2012b) explained several internal and interpersonal motivating factors that makes games enjoyable to players. These motivational factors were taken from the Taxonomy of Intrinsic Motivations for Learning developed by Malone and Lepper (1987). This taxonomy included seven intrinsic motivations that need to be considered when developing gamified instruction to make it fun and engaging. Internal factors include: challenge based on goals, feedback, and uncertain outcomes; curiosity and inquiry; and control over choice and power. Interpersonal factors include cooperation between team members, competition between teams or individuals, and recognition of hard work that is visible to others. Using these factors as guidance for designing curriculum, the focus of the game moves toward the user experience 
and how these factors influence learning and interaction with the gamified content (Koivisto \& Hamari, 2014). The omission of these intrinsic motivators may create disinterest in the game and have an adverse effect on learning. Good game design, then, requires that designers take these factors into account and apply them to the gamified experience.

\subsection{Gamification in Classroom Settings}

Many recent studies have shown how gamification has been applied successfully to learning environments. One study found that changing the structure of a course into a competitive game had a strong impact on helping students learn their educational identity (Charles et al., 2010). The researchers found that students who played the game and received feedback for their actions enjoyed the experience more, learned more, and had lower rates of failure than members in class sections from previous years. In another study, students noted that they were more motivated and interested in a gamified course compared to other courses they had taken (Barata et al., 2015). These students were also more proactive and willing to participate in a gamified course compared to their non-gamified courses. Ibáñez, Di-Serio, \& Delgado-Kloos (2014) found that gamification helped students to develop knowledge in a programming course. The course was developed using leaderboards and badges that were visible to peers and were earned by completing specific tasks. Abrams and Walsh (2014) found that students who took part in a gamified vocabulary unit were motivated to practice words on their own because they were engaged in learning through gameplay. The common thread throughout these studies is that students were intrinsically motivated to learn and found enjoyment in the act of learning.
While not all gamified experiences are successful, researchers have found that games have positive effects on student learning. For example, Vos et al. (2011) found that using game design elements have the capability of enhancing student motivation and critical thinking while playing the game. Carefully selecting game elements that align with learning content can improve student learning outcomes and help them develop motivation to learn. Another study found that some students may benefit from mechanisms that show progress, such as progress bars or completion percentages, because students can view their progress and view feedback to improve their status (Chen, Chao, Hsu, \& Teng, 2013). Other systems have been generated that address fairness in group work. For example, one study discussed how a game platform encouraged students to contribute and collaborate (Moccozet, Tardy, Opprecht, \& Leonard, 2013). Although students were grouped together, each student had to show personal contributions to the gamified experience to benefit the whole team. This helped to reduce the amount of students who were passively participating in the activity and allowing others to do their work for them.

In all, recent research has shown that gamification is a viable tool for improving student learning and increasing motivation. Studies have found that intrinsic motivation increases with the introduction of gamification to a curriculum (Banfield \& Wilkerson, 2014; Lamprinou \& Paraskeva, 2015), and that the increase in intrinsic motivation can improve learning achievement (Su \& Cheng, 2014). With the novelty that gamification offers and the motivation it provides for students to learn new content, gamification should be explored more fully to determine what qualities of games create the best game design. Again, this study focuses on exploring the effects of intrinsic motivation factors on students' gamified learning outcomes. 


\section{Method}

For this study, a gamified unit on photography skill learning was developed for a middle school class. The game, titled CLICK, was developed to provide students with new information about photo composition in a gamified setting. The game was purposefully designed with Malone and Lepper's Taxonomy on Intrinsic Motivations for Learning (1987) to determine which components or factors had an effect on learning outcomes.

\subsection{Participants}

Participants for this study were students from an urban middle school in a western state of the United States who were enrolled in a semester-long media class. The students in this class were learning photography and videography skills that were used in other course projects. Participants who took part in this study were in $7^{\text {th }}$ or $8^{\text {th }}$ grade and displayed a variety of academic and photography skill levels.

In total, 146 participants were used in the study, including 63 females and 83 males. To obtain the desired number of participants, the study was conducted over two consecutive semesters of the media course. There were 69 participants from the spring semester and 77 participants from the fall semester.

\subsection{Gamified Curriculum Development}

For the photography unit, a new game called CLICK was developed by the researcher to teach photography skills. The game was developed to provide students with the opportunity to interact with a variety of shot distances, angles, and challenges to complete while competing against classmates for points. The six intrinsically motivating factors (challenge, curiosity, control, cooperation, competition, and recognition) were carefully integrated into the game experience design. One motivating factor, fantasy, was not explored in this study due to the possibility that the photography unit did not create an imaginative world that students would get in other experiences, such as being a scientist in a gamified science unit.

Challenge. Challenge was addressed through the rules, goals, and feedback embedded in the game design. The rules for the game were modified from the game HORSE so that students had specific guidelines to follow to make the game fair. The goal of the game was to earn points by taking the best photo each round that met established criteria, which in turn led to the larger goal of winning the game. At the end of each round, each picture was given specific, targeted feedback about the good and bad qualities of the photo that could be used to improve skills in later rounds. This feedback targeted common errors in photography, such as cutting off subjects, distance issues, and lighting and shadowing problems, and were expected to be fixed in future rounds.

Curiosity. Curiosity was embedded in the gamified design because students were required to develop new skills and expand on them in short time periods. Students who were novices in the first round were able to improve their skills through experience in later rounds by exploring new techniques and applying information they learned from text and peer guidance. The natural curiosity to improve skills due to the skill level increase of their peers may have motivated students to take better photos each round. Uncertain outcomes also played a factor in student curiosity because students were not aware of their shot quality compared to others until their picture was shown with pictures from other teams, which created motivation to take several 
good pictures and submit the best from that sampling.

Control. Control was established in this game based on how teams chose to complete the objective for each round. The criteria for each shot was purposefully vague so that students could choose the components of their photo, but included enough constraints so that comparisons could be made between similar pictures. This allowed students to turn in unique photos that did not look exactly the same as their peers, but contained the same elements so that comparisons could be made in shot qualities.

Cooperation. Cooperation was built into the gamified design through the use of self-selected pairs. The pairs were able to collaborate to make decisions about the composition of their photo to improve their chance of success each round. They were also required to collaborate with other teams to complete tasks such as taking a photo with two or more people in the shot. Working with a partner provided students with the opportunity to develop more creative solutions and turn in a better picture.

Competition. Since the ultimate objective of the game was to win, students competed against other teams for points each round. As the goal of the game was to improve skills each round, the competitive aspect of the game created a natural drive for each team to want to do better than those around them. This friendly competition helped students to improve their skills quickly so that they could remain competitive throughout the game.

Recognition. Finally, recognition was used to praise students for their successful application of photography skills when pictures were shown to the class and compared against each other. Along with providing focused feedback to improve for the next round, students were recognized for the good qualities of their photos and were provided with a opportunity to take pride in their work and have it seen by others. Student work was recognized each round with verbal praise and through the distribution of points.

\subsection{Instruments}

Two instruments were created to collect data for this study. The first instrument was the Intrinsic Motivations Survey, which asked participants questions about the six intrinsically motivating factors they encountered while playing the game. The second instrument was a photography skills test that measured student knowledge of photography principles learned during the game.

\subsubsection{Intrinsic Motivations Survey}

The Intrinsic Motivations Survey was developed by the researcher and included questions based on the six motivational factors originally introduced by Malone and Lepper (1987) and discussed by Kapp (2012b) as necessary for designing engaging and motivating gamified lessons. At the beginning of the survey, three general questions about student views on using games for learning were asked. These introductory questions were followed by questions on the six motivational factors found in gamified design.

The survey contained six sections based on each intrinsic and interpersonal motivation, and each section included six questions that were measured using Likert-type scales. The questions and responses were put into a grid so that participants could easily identify which responses they wanted. Participants responded to each question by placing an $\mathrm{X}$ in the table across from the question and below their response. The response options were very 
strongly disagree (VSD), strongly disagree (SD), disagree (D), agree (A), strongly agree (SA), and very strongly agree (VSA). The responses provided by participants were changed to a numerical value, with VSD scored as a zero and VSA scored as a five. Scores for each block were added together so that total scores for each section could be analyzed against each other. The highest possible score for each section was 30 points.

The survey concluded with five openended questions that asked about specific aspects of the gamified experience. Students were asked what they liked, disliked, found easy, and found difficult about the game. The final question provided students with the opportunity to provide feedback that did not necessarily fit any of the other four questions.

Following the advice of Krosnick and Presser (2010), each question stem in this survey was made using a positive statement. This was important to do because adolescents may not be cognitively able to answer negative statements in an affirmative manner, which could cause them to give the opposite answer they intended (The London School of Economic and Political Science, 2010). For example, adolescents who are provided with negatively-worded stems may answer with agree when they meant to answer with disagree. Therefore, negatively-worded stems were not used so that errors were avoided in intended responses (Colosi, 2005).

Since the survey was a new instrument developed for this study, a pilot study was conducted to determine reliability of the instrument. Factor analysis was conducted to determine what, if any, underlying structures existed between the questions developed for the six predictor variables used in this study (challenge, control, curiosity, cooperation, competition, and recognition). Factor analysis was conducted on 47 random surveys and included eigenvalue, variance, scree plot, and residual analysis. From the analysis, a seven-component solution was generated that accounted for $79.4 \%$ of total variance for responses from all variables, which would suggest that the survey was reliable for use in this study. The survey was also examined for face validity by an expert in gamification (Sprinthall, 2012) and was found to have validity since it measured the constructs associated with gamification.

\subsubsection{Photography Skills Test}

The test of photography skills used in this study was developed based on the material students learned during the game. The test consisted of ten matching questions, eight multiple-choice questions, six fill-in-the-blank questions, and two long answer/constructed response questions. Questions were developed based on the photography skills guidance that was given to students before the game began. The highest possible score that students could earn on the test was 70 points.

\subsection{Procedures}

\subsubsection{Gamified Unit Pre-Game Setup}

On the first day of the study, students chose a partner to work with for the duration of the game. Students were allowed to select their partner because prior research has shown that self-selected groups tend to perform better and have better experiences than randomly assigned groups in short-term activities (Chapman, Meuter, Toy, \& Wright, 2006; Moreland, Levine, \& Wingert, 1996; Rientes, Alcott, \& Jindal-Snape, 2014). Study participants were also able to select a partner from students who did not receive parental consent to participate so that they could play the game with a familiar classmate.

After partners were selected, each pair 
was given a guidance sheet with information about photograph composition, including shot distances, angles, framing, and other basic photography information. Students were also provided with game rules, including scoring, time limits, and photo submission to be considered at the end of the round. Each pair of students was assigned one iPad to take pictures so that photos could be transferred to a teacher iPad and to avoid technological advantages from other devices.

\subsubsection{Game Flow}

For the first round of the game, the instructor provided shot criteria that each pair was required to use in their photo. Every pair was given the same initial shot criteria, which was "Take an eye-level mid-shot portrait of one of your group members." Students were given five minutes to reference the guidance sheets they were provided and decide the best shot to compose with their partner. Students used the Camera app on the iPad, but could not zoom in or use photo options such as square or panorama. Students were also prohibited from altering their photo using camera tools or editing programs. When students were confident that they had composed their best picture, they transferred their picture to the instructor's iPad using the Airdrop function. This allowed students to submit their photos anonymously so that there was fairness in the photo evaluation process.

When all pairs had submitted their photos or the submission time period had expired, the instructor displayed the photos on a large screen by transmitting them from the iPad using the AirServer app to the school computer and projector. As each picture was shown on the screen, the instructor highlighted strengths and weaknesses of each photo based on the handout guidance students were expected to use. Students who met all of the round criteria were awarded with one letter toward the word CLICK and one photo was determined the overall winner of the round.

For the next several rounds, teams were given new shot criteria determined by the instructor. This helped to ensure that students received criteria for every shot type, angle, and distance that would be evaluated on the photography skills test and used in later class projects. There were instances in some class sections where one pair of students was able to complete CLICK and a new game was started. During that game, the pair with the overall best picture in the previous round was given the opportunity to decide shot criteria for the class to use for the next picture. The game was played over seven days, which included five 40-minute class periods and two 80-minute class periods.

\subsubsection{Survey and Test Delivery}

On the eighth day of the study, each student was given the Intrinsic Motivations Survey to complete individually. Students were given 40 minutes to complete the survey so that they had time to think about and provide feedback about their motivation to learn and experiences in the gamified unit. On the final day of the study, students were given an unannounced test on the photography skills learned during the game. Students were not notified of the test beforehand so that there was a reduced chance that they would study outside of class or seek out additional materials that would give them an advantage over their peers and interfere with the reliability of the findings in this study. Students were given a complete block period of 80 minutes to finish the test.

In total, the game, survey, and test took nine class periods to complete. The study took place over six 40-minute class periods and three 80-minute block periods. 


\section{Data Analysis and Results}

The purpose of this study was to explore which of the six motivational variables defined by Malone and Lepper (1987) had an effect on learning outcomes in a photography unit. Specifically, this study was guided by this research question: Which motivational variables have a direct or indirect effect on participant's gamified photography skills learning? The data collected from the Intrinsic Motivations Survey and the photography test were analyzed using the SEM analysis of maximum likelihood estimation (ML) using the STATA/SE 14.2 statistical analysis software. ML was selected because it estimates the likelihood that the data matches to the maximum extent with the population it was drawn from (Berkout, Gross, \& Young, 2014; Kline, 2011). Using prior research related to the six motivational variables, a theoretical model was developed linking the six predictor variables (challenge, curiosity, control, cooperation, competition, and recognition) to the criterion variable (scores on a photography skills test). Figure 1 shows the theoretical model and Table 1 shows the intrinsically motivating factors labeled on the figure.

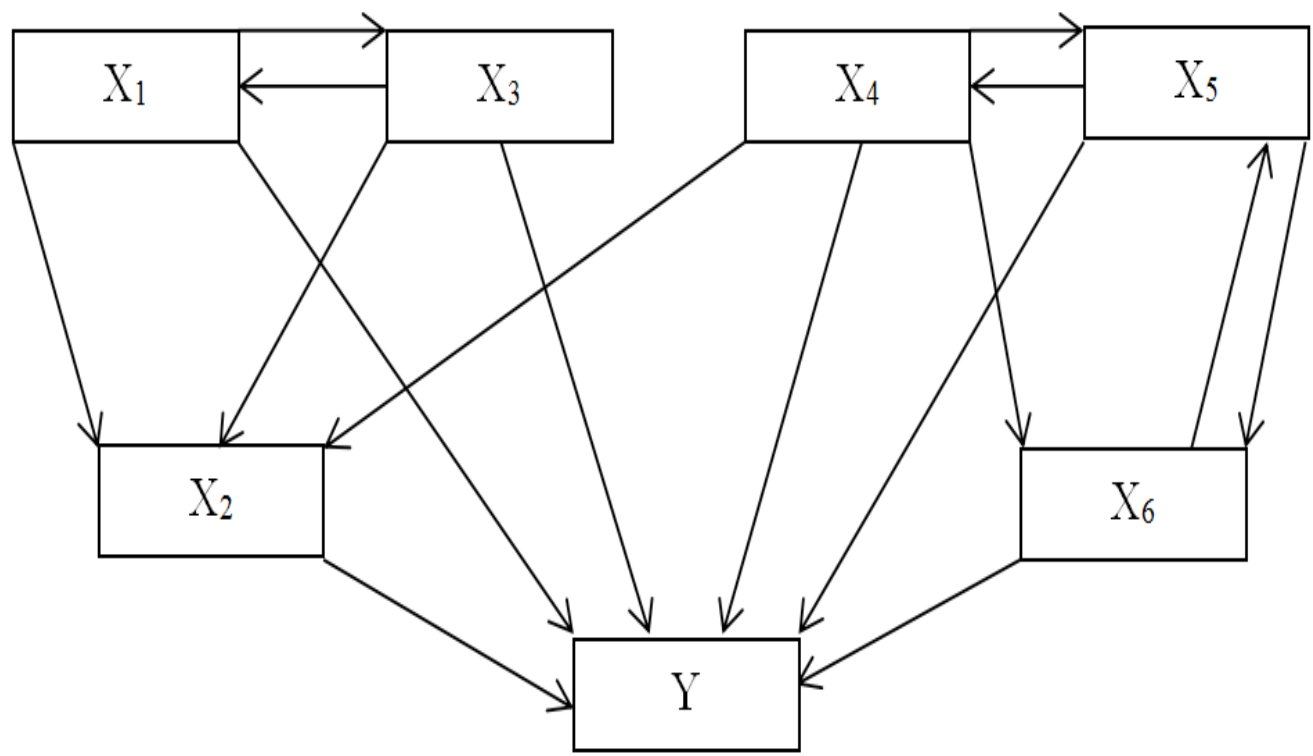

Figure 1. Conceptual model of variable relationships.

The conceptual model was analyzed using four goodness-of-fit statistics to determine if the model was a good fit for the data. First, the model Chi-square was used to test the exact-fit hypothesis that there are "no discrepancies between the population covariance and those predicted by the model" (Kline, 2011, p. 199). Second, the root mean square error of approximation (RMSEA) was used to determine goodness-of-fit based on a 
parsimonious model (Kline, 2011). Finally, the Bentler Comparative Fit Index (CFI) and Tucker-Lewis Index (TLI) were selected because they measure whether the final model is an acceptable fit to the data compared to the initial model (Cangur \& Ercan, 2015; Kline, 2011).

Prior to the model analysis, preliminary correlations were conducted on the six predictor variables and one criterion variables used in the conceptual model. Findings revealed that there were significant correlations between the predictor variables at the $p<.01$ level, but only one predictor variable, curiosity, was correlated with test scores $(p=.014)$. The correlation values can be found in Table 2 .

Table 1. Variable Descriptions

\begin{tabular}{|c|c|}
\hline Variable & Variable Description \\
\hline $\mathrm{Y}$ & Score on a photography skills test \\
\hline $\mathrm{X} 1$ & Challenge \\
\hline $\mathrm{X} 2$ & Curiosity \\
\hline $\mathrm{X} 3$ & Control \\
\hline $\mathrm{X} 4$ & Cooperation \\
\hline $\mathrm{X} 5$ & Competition \\
\hline $\mathrm{X} 6$ & Recognition \\
\hline
\end{tabular}

Table 2. Preliminary Correlations from Initial Model

\begin{tabular}{|c|c|c|c|c|c|c|c|}
\hline & $\mathrm{X} 1$ & $\mathrm{X} 2$ & $\mathrm{X} 3$ & $\mathrm{X} 4$ & $\mathrm{X} 5$ & $\mathrm{X} 6$ & $\mathrm{Y}$ \\
\hline $\mathrm{X} 1$ & 1.000 & & & & & & \\
\hline $\mathrm{X} 2$ & $.790 * *$ & 1.000 & & & & & \\
\hline $\mathrm{X} 3$ & $.752 * *$ & $.805^{* *}$ & 1.000 & & & & \\
\hline $\mathrm{X} 4$ & $.404 * *$ & $.404 * *$ & $.458^{* *}$ & 1.000 & & & \\
\hline $\mathrm{X} 5$ & $.660^{* *}$ & $.703^{* *}$ & $.709^{* *}$ & $.351 * *$ & 1.000 & & \\
\hline $\mathrm{X} 6$ & $.728^{* *}$ & $.821^{* *}$ & $.838^{* *}$ & $.460 * *$ & $.807 * *$ & 1.000 & \\
\hline $\mathrm{Y}$ & .080 & $.214^{*}$ & .043 & -.040 & .171 & .096 & 1.000 \\
\hline
\end{tabular}

$* *=$ significant at $\mathrm{p}<.01 \quad *=$ significant at $\mathrm{p}<.05$

The first test of the conceptual model found that the model could not be estimated. To remedy this, one arrow was removed from variables that had two single-headed arrows between them so that the STATA/SE 14.2 software could develop an initial estimated model. Arrows were removed from control to challenge, recognition to competition, and competition to cooperation so that only one arrow connected each pair of variables. These 
changes allowed the program to produce an estimated model.

In total the model was altered and tested 15 times to improve the findings from the four goodness-of-fit tests. The final model was found to be an excellent fit for the data (Model $\chi^{2}(10)=9.35, p=.499$; RMSEA $<.001$; CFI $=1.000 ;$ TLI $=1.002$ ). Table 3 shows a summary of the model alterations, Figure 2 shows a diagram of the final model with standardized correlations, and the intrinsically

Table 3. Summary of Model Changes

\begin{tabular}{|l|c|c|c|c|c|c|}
\hline \multicolumn{1}{|c|}{ Alteration } & df & $\begin{array}{c}\text { Model } \\
\chi^{2}\end{array}$ & $\begin{array}{c}\text { Model } \boldsymbol{\chi}^{2} \\
\boldsymbol{p}\end{array}$ & RMSEA & CFI & TLI \\
\hline Conceptual Model & 7 & 174.32 & $<.001$ & .427 & .730 & .230 \\
\hline cooperation to curiosity removed & 8 & 174.39 & $<.001$ & .398 & .732 & .330 \\
\hline cooperation to test score removed & 9 & 175.10 & $<.001$ & .375 & .732 & .405 \\
\hline recognition to test score removed & 10 & 175.10 & $<.001$ & .356 & .732 & .464 \\
\hline challenge to test score removed & 11 & 177.79 & $<.001$ & .340 & .731 & .511 \\
\hline competition to test score removed & 12 & 179.55 & $<.001$ & .326 & .730 & .550 \\
\hline curiosity to competition added & 11 & 106.12 & $<.001$ & .257 & .847 & .721 \\
\hline cooperation to competition removed & 12 & 107.49 & $<.001$ & .246 & .846 & .744 \\
\hline curiosity to recognition added & 11 & 55.12 & $<.001$ & .175 & .929 & .871 \\
\hline control to recognition added & 10 & 33.07 & $<.001$ & .133 & .963 & .926 \\
\hline cooperation to recognition removed & 11 & 36.12 & $<.001$ & .132 & .960 & .926 \\
\hline recognition to competition added & 10 & 20.09 & .028 & .088 & .984 & .967 \\
\hline competition to recognition removed & 11 & 20.62 & .038 & .082 & .985 & .972 \\
\hline curiosity to competition removed & 12 & 22.52 & .032 & .082 & .983 & .972 \\
\hline cooperation to control added & 11 & 13.65 & .253 & .043 & .996 & .992 \\
\hline challenge to competition added & 10 & 9.35 & .499 & $<.001$ & 1.000 & 1.002 \\
\hline
\end{tabular}

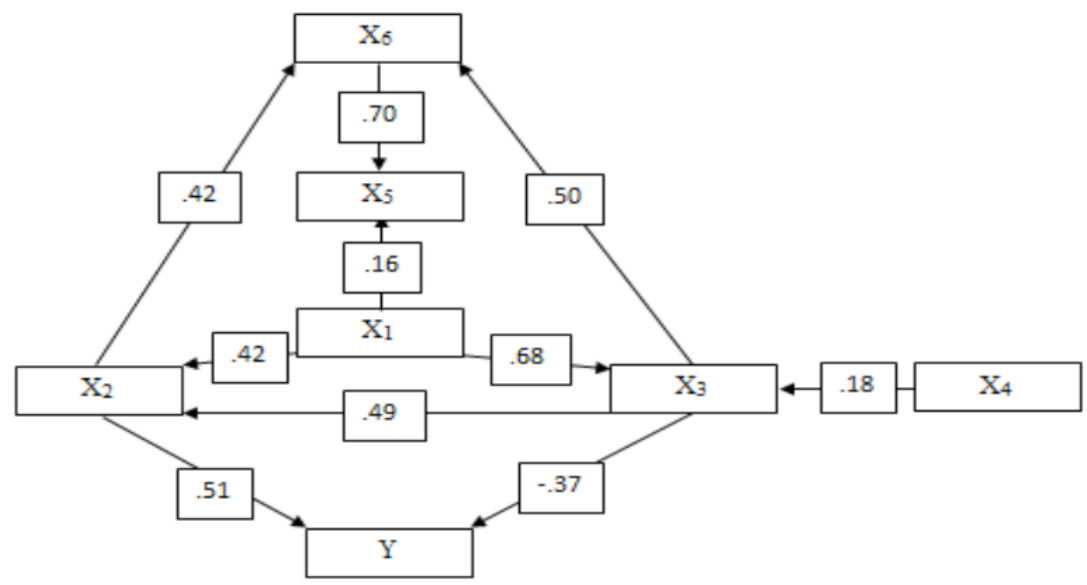

Figure 2. Final model with standardized correlations. 
motivating variable labeled on the model can be seen in Table 1 .

Variables with Effects on Test Scores. The final model contained two direct paths and six indirect paths between predictor variables and test scores. The direct effect of curiosity on test scores was $.51(z=3.65, p<.001)$, while the direct effect of control on test scores was $-.37(z=-2.64, p=.008)$. Control also had an indirect effect through curiosity on test scores of $.25(z=3.24, p=.001)$.

The variable challenge had three indirect paths to test scores. The first path (challenge to curiosity to test scores) had an effect size of .21 , the second path (challenge to control to curiosity to test scores) had an effect size of .17 , and the third path (challenge to control to test scores) had an effect size of -.25. The total indirect effect of challenge on test scores was .13 and was found to be significant $(z=1.99$, $p=.047)$.

\section{Discussion}

The final SEM model showed that three variables (curiosity, control, and challenge) had a direct and/or indirect effect on test scores. Each of these variables will be explored to explain their effects on student learning and on each other.

\subsection{Curiosity}

Curiosity was the intrinsically motivating factor that was found to have an effect on test scores across all analyses in this study. This was expected because curiosity is the "most direct intrinsic motivation for learning" (Malone \& Lepper, 1987, p. 235). Curiosity is necessary in gamified environments because the ability to improve skills through questioning and information gathering is needed to improve skills and performance
(Stokoe, 2012). For a gamified experience to be effective, participants must have curiosity and an internal drive to want to learn more.

In the photography game, students were required to be curious because they were provided with limited information and had to seek out knowledge of photography principles to improve each round (Morris et al., 2013). Students needed to ask questions about how they could improve their skills, adjust their method of taking pictures based on previous performance, and seek information to fill in gaps in understanding. Through their own innate curiosity, students were able to acquire and develop skills, learn new concepts about photography, and improve their photography knowledge.

Student feedback provided information about how they used curiosity while playing the game. One student noted that they enjoyed the game because "we could be creative and take shots of anyone or anything." Another student wrote that playing the game "gave me the opportunity to achieve higher standards and learn new things." With the ability to try new things without the fear of failure, students had the opportunity to determine the best course of action to complete a goal (Kapp, 2012a; Dicheva et al., 2015; McGonigal, 2011). When students are able to try new things and discover working solutions to problems, they are able to raise their standards and achieve higher levels of learning. Ensuring that curiosity is fostered in a gamified experience is necessary to help motivate students to learn new content and develop better skills.

\subsection{Control}

The second intrinsically motivating factor to have an impact on test scores was control. Surprisingly, control had a direct negative 
impact on student learning even though students had the ability to make choices about how they completed tasks within the rules of the game (Lee \& Hammer, 2011). The experience was designed so that students had the ability to take different photos within the same parameters, but some other constructs appeared to impact the experience they had with the game. One component that appeared to have an effect on control was the inclusion of student-selected partners.

The use of partners had an impact on the control dynamics in the game experience. For example, partners who did not interact well had problems with completing tasks due to the inability to make decisions together about the best course of action. Feedback from students about partner dynamics showed that there were many issues that affected the game experience, including one partner dominating the use of the camera, lack of compromise when deciding what photo to take, and offtask and unhelpful behaviors that impeded progress toward the goal. Control issues appeared to magnify when two people were expected to come to an agreement about how to complete a task, which caused students to have power struggles, disinterest in the game, and impaired learning of photography skills and tools.

If students were able to overcome these control issues and work together toward a common goal, they were able to foster curiosity in learning that created a positive impact on their experience. When students had a common goal and understanding of how to complete it, they were able to share information and understanding of photography skills and grow together. Cooperating with each other created a better relationship between partners that allowed them to be curious and learn (McGonigal, 2011), as opposed to the students who were fighting each other for control. One student who shared control and was able to be curious noted that "collaborating with my partner let me turn in much better photos than if I were to do it alone." Being able to share ideas, work together, and avoid imbalances in control motivated some students to learn because they could be curious and in control of their learning (Vos et al., 2011).

\subsection{Challenge}

Challenges in the game were needed to test player skills and provide opportunities for participants to develop solutions using trialand-error (Gumulak \& Webber, 2011). These challenges affected curiosity and control in the game experience, which influenced how partners completed goals and learned new material. The effects of challenges expand on what was previously discussed about curiosity and control.

Challenges in games include goals, uncertain outcomes, feedback, and selfesteem (Malone \& Lepper, 1987). At the start of each round, students were presented with specific criteria to use to take a photo. Students knew that their photo had the potential to earn points, but their submission was not guaranteed to win points each round. Feedback was provided on pictures each round to show how they met criteria and where improvements could be made for subsequent rounds. Since students were being judged and recognized based on what they could do, it was expected that they would have improved self-esteem in regards to photography skills.

Challenge had a positive indirect effect on test scores when the challenges presented in the game caused students to be curious to learn new photography skills and drove them to improve their abilities. Students who sought out new information from the guidance and 
from their peers improved their knowledge of photography as they completed objectives. Similar to findings in other studies, it appeared that students who were challenged by game objectives were more engaged and attempting to learn new content (Hamari, Shernoff, Rowe, Coller, \& Edwards, 2016). Increasing the difficulty in each round and testing student skills caused them to be curious about their learning and seek opportunities to improve their abilities.

Challenge also had an indirect effect on test scores through control. The indirect effect of challenge on test scores through control had a negative effect, but the branch that went through control to curiosity had a positive effect. The issues discussed earlier with the direct and indirect effects of control on test scores appear to be related to how participants completed challenges.

In a gamified experience, challenge goals require participants to decide the best course of action to complete them. If participants were able to work together to complete the goal, they could apply knowledge and feedback to come to a solution on what would work best based on prior experience. Having both individuals in the game working together helped to raise knowledge, skills, and selfesteem that inspired them to learn more about photography. However, control issues caused the opposite effect on learning when participants were not able to work together to complete challenges. When participants felt that their input was not being heard or that their partner was not contributing as much as they could, self-esteem was negatively affected, which in turn had a negative effect on learning.

Student comments about their game experience focused highly on the use of feedback related to challenges. Feedback is one of the critical components of a game, since it can lead to curiosity and skills improvement (Kapp, 2012a; Morris et al., 2013; Saunderson, 2011). With the feedback provided each round, students were able to improve their skills and enjoy playing the game. Students provided a variety of points of view that can be helpful when creating gamified experiences. One student enjoyed receiving feedback on their pictures because they were "given chances to continue improving." The feedback helped students to improve their skills, which meant that "rounds got easier based on prior experience." However, one student noted that feedback was "not given to winners when they need it." It is important to remember that some students may be looking to improve the fine details of their work and still need feedback regardless of the photo quality. Providing feedback for photos each round gave students new information to increase their curiosity about learning photography skills, which in turn may have improved their learning outcomes.

\section{Implications}

The findings of this study can be used to drive future research and help teachers and instructional designers to develop gamified curriculum. This section includes suggestions about how the results of this study apply to current and future research. It also includes suggestions for applications to teaching and learning so that teachers and instructional designers can apply these findings to their own gamified design.

\subsection{Research Implications}

One of the main purposes of this study was to explore the effects of gamification at the secondary education level. Previous studies have noted that very few studies examined 
the effects of gamification on learning at the secondary education level (de Sousa Borges et al., 2014; Dicheva et al., 2015). This study provides information about which intrinsically motivating factors predict learning outcomes and have an effect on test scores for middle school students.

This study focused on the six intrinsically motivating variables and their ability to predict test scores. This creates several avenues for research to further explore gamification and its effects on learning. One variable in particular, cooperation, needs to be explored further to discover how it can fit better in a gamified design. In this study, cooperation was found to be a fringe factor in the SEM model that did not influence test scores. One explanation may be that students were required to work with partners during the game, which is not always a requirement when playing games not designed for educational purposes. Studies can be done that focus on the role of cooperation in gamified learning environments and whether using individuals, pairs, or larger groups have an impact in learning outcomes.

While this study focused on middle school students, the findings can be used to inform gamified design for primary school students, high school students, and higher education. This study was structured so that students were given enough guidance to complete round requirements while still maintaining a sense of curiosity about their learning. The structure of this study can be altered to fit the needs of students at lower and higher grade levels. For example, students in a primary school setting may need more structure and smaller goals to achieve to remain interested in the game. Conversely, students in higher education can be given more freedom and less structure so that they are required to be curious and collect topic information on their own. Research can be done on the balance of freedom and structure to determine what the best combination is for each level of learner.

The findings of this study can also inform experimental research on gamified learning. As was stated earlier, this study explored the predictive nature of the six motivational factors on test scores. Future research could explore the effect of this and other gamified lessons on learning outcomes compared to traditional teaching methods to determine if they lead to improved learning outcomes.

\subsection{Applied Implications}

Based on the findings from the SEM model, several suggestions can be made for gamified design applications that can benefit teaching and learning. The data collected in this study showed that each predictor variable had an impact on the game experience, but only a few influenced test scores. Gamified lesson designers will want to consider the following items when creating their gamified experience.

Study variables and game design. Curiosity is the most important variable that needs to be accounted for when developing a gamified experience. When students seek out information or discover new solutions to a problem, they are in charge of their learning and become responsible for finding out as much as possible about it. For students to be curious, constructs in the game need to be embedded that require students to seek out answers and improve their knowledge of the topics learned in the game (Gumulak \& Webber, 2011). If students are not required to be curious in a gamified experience, they may become disinterested in learning and miss out on opportunities to enhance skills and knowledge. Gamified lesson designers need to ensure that curiosity is a focal point of 
their design since several other motivational factors use curiosity as a pathway to influence learning outcomes.

A second factor that needs to be accounted for in gamified design is control. As noted in this study, control issues had a negative effect on test scores because some pairs had imbalances in responsibilities and input each round. To minimize the negative effects of control, the gamified design needs to include rules and constructs that require partners to have equal representation in the game. One item that will need to be changed for future studies is an update to the rules and guidance to require partners to switch responsibilities every round so that each partner has equal access to the camera and decisions about how to complete goals. This may help students to learn to cooperate better and come to a shared decision so that both partners are responsible for their submission each round.

Curiosity and control had a direct effect on test scores in this game, but they were not the only factors that had an effect on test scores. With these two intrinsically motivating factors accounted for, the designer will need to focus on making sure the challenge aspects of the game are clearly defined. Since challenge has an indirect effect on test scores, instructional designers will need to make sure that there are goals, uncertain outcomes, and feedback to help students move forward in the game. Providing students with clear information can help students to improve their self-esteem as they succeed in performing tasks.

Finally, instructional designers will need to complete the game experience by developing cooperation, competition, and recognition structures that help motivate students to learn new content. Providing opportunities for students to work together and against each other can motivate them to work harder to improve their skills. Recognizing successes with an extrinsic motivator that matches the level of effort used can further motivate students to learn new material while playing the game (Wang \& Sun, 2011).

Suggestions for classroom application. The gamified photography curriculum used in this study provided students with the opportunity to be intrinsically motivated to learn and engaged while playing the game. Games have the ability to increase engagement because humans are naturally interested in playing games and can be motivated to learn when using them (Apostol et al., 2013; Barata et al., 2015; Bíró, 2013; Measles \& AbuDawood, 2015). These suggestions can help to create an engaging gamified experience for students.

When developing a gamified unit, it is important to remember that students are expected to have fun while learning. Students should be provided with opportunities to discover knowledge on their own and interact with their peers so that they create a shared fund of knowledge (Barata et al., 2015). This means that participants need to be able to move around, share ideas, and come to an understanding of the content through interactions with the teacher and peers. The teacher is not a sole source of knowledge in a gamified setting, but is a facilitator of learning and helps their students to become more curious about the content they are learning.

One of the items that may have negatively impacted this study was the cooperation component of this gamified design. As was noted in the study, cooperation did not have a significant effect on test scores even though students were required to cooperate with 
partners and other students in the class. There are several suggestions that can improve cooperation between students. One idea that could improve cooperation would be to have students work alone to take photos, but have to work with others to take photos that require more than one person. This would allow students to turn in photos that they deem to be high quality and have the opportunity to gather information from other players that could benefit their learning. However, this approach would require one-to-one technology access to devices from a single company, such as Apple, so that each student has a device and can share photos with the teacher easily.

A final item to consider when applying gamified design is that it takes time to develop an engaging experience (Cheong et al., 2014). Careful planning and idea development need to be done to create an engaging experience. If every component of a gamified design is not thought through or embedded properly, students can become disengaged and disinterested in learning (Kapp, 2012b). The development cycle for this game included a significant amount of work, including decisions about what game to derive rules and structure from and what learning content would be a good fit for the game. Although it is time consuming, the rewards for building a game that motivates students to learn makes developing gamified lessons worthwhile.

\section{Conclusion}

Based on the findings from this study, two of the six intrinsically motivating factors detailed by Malone and Lepper (1987) as necessary to create a gamified experience had a direct effect on test scores in a photography unit. These factors, curiosity and control, need to be thoughtfully integrated and moderated in gamified learning experiences to ensure that students are motivated to learn new material and can apply that knowledge to content assessments. In summary, two main conclusions can be drawn.

First, for a gamified learning experience to be effective, structures need to be meaningfully integrated into the game experience that cause students to be curious about their learning and want to learn more about the topic at hand. Therefore, gamified instructional designers need to develop structures within the game that increase student curiosity to learn new material. When designing a gamified experience, instructional designers need to focus the game so that students seek out new information that expands their content knowledge within the rules of play. This can be accomplished by creating structures that cause students to find information based on clues and incomplete information or by providing on-the-spot information that students need to think about before applying it to the game. If the gamified experience includes embedded structures that require students to take control of their learning and find an intrinsic desire to learn new information on their own, students may learn to be curious, independent, selfmotivated learners who enjoy learning new material.

Second, gamified instructional designers need to embed rules and structure in the game that minimize the effects of control regarding team dynamics and devices and maximize the effect of being in control of how new information is acquired. There are many issues with control that can negatively impact the game experience and content learning. Setting up rules that determine how frequently a student can use a device or who acts as the team leader each round may help students to focus on completing goals for a round instead of struggling for power over team functions. These structures can help students to find their voice and become a valued member of a team 
that works productively toward completing a task. Applying more rules to guide the game experience and create equal partners in a team dynamic can move the focus away from controlling others on a team to controlling the knowledge to be gained and can lead to shared curiosity in learning.

Finally, gamified instructional designers need to develop challenge structures that enhance the game experience and lead to curiosity and shared control. Challenges need to be created through the development of rules and goals that govern what students are allowed to do during game play. Rule sets should be derived from games students are familiar with so that less time is used explaining how the game is played. The use of existing game rule structures can allow for more time playing the game, which can improve engagement and motivation to learn. Game goals must include a degree of difficulty that requires students to seek out information to improve their knowledge and skills. The inclusion of structures that force students to find information can lead to improved curiosity and a deeper understanding of content material. Finally, structures need to be developed that cause uncertain outcomes so that students do not know if they have completed a goal until the end. These structures need to be included so that students are motivated to keep working until they have fully completed a goal. The proper application of challenge can influence learning outcomes due to the improvement of curiosity to learn and the shared responsibility to discover new information that comes when control is shared between game participants.

\section{Limitations}

While there were many findings in the study that can help to improve teaching and learning and drive research in gamification, several limitations affect the study findings. These limitations may have an effect on the generalizability and usefulness of the findings.

The first limitation to this study was that the study researcher was also the game developer and the evaluator for learning outcomes. This may have had an impact on several items in the game that involved students. For example, students may have answered questions on the Intrinsic Motivations Survey differently than they would have if the game had been administered by another teacher. This influence on survey responses may have skewed data toward more positive findings that may not be similar to other classes who implement the gamified curriculum.

A second limitation for this study was that the game was built for a photography unit. The gamified design worked for the classes that the game was implemented in because there was more freedom in regards to the amount of time that could be spent on the game. Other core content classes may not be able to accommodate a lengthy time period to implement a gamified unit, especially if content needs to be covered for high-stakes testing. For example, math classes may have a required curriculum that they must cover before end-of-course exams or other state tests, which may make it difficult to add gamification to their curriculum. Issues with time constraints in the classroom and time to prepare and deliver the gamified curriculum may make it inaccessible to some teachers. While some design structures in this study may support the development of gamified design in core content areas, there may need to be significant changes to the design process to support student learning in smaller time frames and to allow for other content to be covered before the end of the course. 
A third limitation for this study was that the study did not explore how student experiences in the gamified curriculum differed based on culture, race, and ethnicity, or gender. Some students may have had positive and negative experiences in the game due to their background and how they perceived the game experience. This study did not look to gain insight on how student experiences differed from peers of different ethnicities or genders, which could be used to inform gamified design for classrooms based on demographic populations. While the design of this study may help others to develop a generalized curriculum, more studies will need to be done with diverse groups of learners to identify differences in experiences students have when taking part in a gamified curriculum.

It is the authors' hope that the experiences and findings from this study could be of help to educators who have the same interests in the design of gamified learning. Comments and suggestions are appreciated and will be of reference in further studies.

\section{References}

Abrams, S. S., \& Walsh, S. (2014). Gamified vocabulary: Online resources and enriched language learning. Journal of Adolescent \& Adult Literacy, 58(1), 4958. doi:10.1002/jaal.315

Antin, J., \& Churchill, E. F. (2011, May). Badges in social media: A social psychological perspective. In CHI 2011 Gamification Workshop Proceedings (pp. $1-4)$.

Apostol, S., Zaharescu, L., \& Alexe, I. (2013). Gamification of learning and educational games. In P. Ice (Ed.) The International Scientific Conference eLearning and Software for Education (pp. 67-72).

Barata, G., Gama, S., Jorge, J., \& Gonçalves (2015). Gamification for smarter learning: Tales from the trenches. Smart Learning Environments, 2(10), 1-23. doi 10.1186/ s40561-015-0017-8

Berkling, K., \& Thomas, C. (2013). Gamification of a software engineering course and a detailed analysis of the factors that lead to it's failure. In 2013 International Conference on Interactive Collaborative Learning (ICL), (pp. 525530). Red Hook, NY: IEEE.

Berkout, O. V., Gross, A. M., \& Young, J. (2014). Why so many arrows? Introduction to structural equation modeling for the novitiate user. Clinical Child and Family Psychology Review, 17(3), 217-229.

Borenstein, J. (2011). Robots and the changing workforce. AI \& Society, 26(1), 87-93.

Boyles, T. (2012). 21st century knowledge, skills, and abilities and entrepreneurial competencies: A model for undergraduate entrepreneurship education. Journal of Entrepreneurship Education, 15, 41-55.

Cangur, S., \& Ercan, I. (2015). Comparison of model fit indices used in structural 
equation modeling under multivariate normality. Journal of Modern Applied Statistical Methods, 14(1), 152-167.

Chapman, K. J., Meuter, M., Toy, D., \& Wright, L. (2006). Can't we pick our own groups? The influence of group selection method on group dynamics and outcomes. Journal of Management Education, 30(4), 557-569.

Charles, D., Charles, T., McNeill, M., Bustard, D., \& Black, M. (2011). Game-based feedback for educational multi-user virtual environments. British Journal of Educational Technology, 42(4), 638-654. doi:10.1111/j.1467-8535.2010.01068.x

Chen, Z., Chao, P., Hsu, M., \& Teng, C. (2013). Level up, my-pet: The effects of levelup mechanism of educational agents on student learning. Journal of Educational Technology \& Society, 16(4), 111-121.

Cheong, C., Filippou, J., \& Cheong, F. (2014). Toward the gamification of learning: Investigating student perceptions of game elements. Journal of Information Systems Education, 25(3), 233-244.

Colosi, R. (2005). Negatively worded questions cause respondent confusion. Retrieved from https://www.amstat.org/ sections/SRMS/Proceedings/y2005/Files/ JSM2005-000508.pdf

Cronk, M. (2012). Using gamification to increase student engagement and participation in class discussion. In T. Amiel \& B. Wilson (Eds.), Proceedings of EdMedia: World Conference on Educational Media and Technology 2012 (pp. 311-315). Association for the Advancement of Computing in Education (AACE).

de Sousa Borges, S., Durelli, V. H., Reis, H. M., \& Isotani, S. (2014, March). A systematic mapping on gamification applied to education. In Proceedings of the 29th Annual ACM Symposium on Applied Computing (pp. 216-222). ACM.
Deterding, S., Dixon, D., Khaled, R., \& Nacke, L. (2011). From game design elements to gamefulness: Defining "gamification". In A. Lugmayr, H. Franssila, C. Safran, \& I. Hammouda (Eds.), MindTrek 2011 (pp. 9-15). doi: $10.1145 / 2181037.2181040$

Dicheva, D., Dichev, C., Agre, G., \& Angelova, G. (2015). Gamification in education: A systematic mapping study. Journal of Educational Technology \& Society, 18(3), 75-88.

Domínguez, A., Saenz-de-Navarrete, J., deMarcos, L., Fernández-Sanz, L., Pagés, C., \& Martínez-Herráiz, J. (2013). Gamifying learning experiences: Practical implications and outcomes. Computers \& Education, 63, 380-392. doi:10.1016/ j.compedu.2012.12.020

Deci, E. L., Ryan, R. M., \& Koester, R. (1999). A meta-analytic review of experiments examining the effects of extrinsic rewards on intrinsic motivation. Psychological Bulletin, 125(6), 627-668.

de-Marcos, L., Domínguez, A., Saenzde-Navarrete, J., \& Pagés, C. (2014). An empirical study comparing gamification and social networking on e-learning. Computers \& Education, 75, 82-91. doi:10.1016/ j.compedu.2014.01.012

Glover, I. (2013). Play As You Learn: Gamification as a Technique for Motivating Learners. In J. Herrington, A. Couros \& V. Irvine (Eds.), Proceedings of EdMedia: World Conference on Educational Media and Technology 2013 (pp. 1999-2008). Association for the Advancement of Computing in Education (AACE).

Groh, F. (2012). Gamification: State of the art definition and utilization. In N. Asaj, B. Könings, M. Poguntke, F. Schaub, B. Wiedersheim, \& M. Weber (Eds.) Proceedings of the 4th Seminar on Research Trends in Media Informatics 
(pp. 39-46). Retrieved from https:// oparu.uni-ulm.de/xmlui/bitstream/ handle/123456789/1800/vts_7866_11380. pdf? sequence $=1 \&$ isAllowed $=\mathrm{y}$

Gumulak, S., \& Webber, S. (2011). Playing video games: Learning and information literacy. Aslib Proceedings,63(2/3), 241255. doi:10.1108/00012531111135682

Hamari, J., Shernoff, D. J., Rowe, E., Coller, B., \& Edwards, T. (2016). Challenging games help students learn: An empirical study on engagement, flow and immersion in game-based learning. Computers in Human Behavior, 54, 170-179.

Ibáñez, M., Di-Serio, A., \& Delgado-Kloos, C. (2014). Gamification for engaging computer science students in learning activities: A case study. IEEE Transactions on Learning Technologies, 7(3), 291-301. doi:10.1109/TLT.2014.2329293

Kapp, K. M. (2012). Games, gamification, and the quest for learner engagement. $\mathrm{T}+\mathrm{D}$, 66(6), 64-68.

Kapp, K. M. (2012). The gamification of learning and instruction: Game-based methods and strategies for training and education (1st ed.). San Francisco: Pfeiffer.

Kim, B. (2015). The popularity of gamification in the mobile and social era. Library Technology Reports, 51(2), 5-9.

Kline, R. B. (2011). Principles and practice of structural equation modeling (3rd ed.). New York, NY: The Guilford Press.

Koivisto, J., \& Hamari, J. (2014). Demographic differences in perceived benefits from gamification. Computers in Human Behavior, 35, 179-188. doi:10.1016/j.chb.2014.03.007

Krosnick, J. A., \& Presser, S. (2010). Question and questionnaire design. In P. V. Marsden \& J. D. Wright (Eds.), Handbook of survey research (2nd ed., pp. 263-313). Bingley, UK: Emerald Group Publishing Limited.
Lamprinou, D., \& Paraskeva, F. (2015). Gamification design framework based on SDT for student motivation. In Proceedings of 2015 International Conference on Interactive Mobile Communication Technologies and Learning (IMCL) (pp. 406-410). IEEE.

Lee, J. J., \& Hammer, J. (20 011 ). Gamification in education: What, how, why bother? Academic Exchange Quarterly, 15(2), 146-151.

Lei, S. A. (2010). Intrinsic and extrinsic motivation: Evaluating benefits and drawbacks from college instructors' perspectives. Journal of Instructional Psychology, 37(2), 153-160.

Malone, T. W., \& Lepper, M. R. (1987). Making learning fun: A taxonomy of intrinsic motivations for learning. In R. E. Snow \& M. J. Farr (Eds.), Aptitude, Learning, and Instruction Volume 3: Conative and Affective Process Analyses (pp. 223-253). Hillsdale, NJ: Lawrence Erlbaum Associates

McGonigal, J. (2011). Reality is broken: Why games make us better and how they can change the world. New York, NY: Penguin Group.

Measles, S. \& Abu-Dawood, S. (2015). Gamification: Game -Based Methods and Strategies to Increase Engagement and Motivation within an eLearning Environment. In D. Slykhuis \& G. Marks (Eds.), Proceedings of Society for Information Technology \& Teacher Education International Conference 2015 (pp. 809-814). Chesapeake, VA: Association for the Advancement of Computing in Education (AACE).

Moccozet, L., Tardy, C., Opprecht, W., \& Leonard, M. (2013). Gamificationbased assessment of group work. In 2013 International Conference on Interactive Collaborative Learning (ICL), (pp. 171179). Red Hook, NY: IEEE. 
Moreland, R. L., Levine, J. M., \& Wingert, M. L. (1996). Creating the ideal group: Composition effects at work. In E.H. Witte \& J. H. Davis (Eds), Understanding Group Behavior: Small Group Processes and Interpersonal Relations Volume 2 (pp. 11-35). Hillsdale, NJ: Lawrence Erlbaum Associates, Inc.

Morford, Z. H., Witts, B. N., Killingsworth, K. J., \& Alavosius, M. P. (2014). Gamification: The intersection between behavior analysis and game design technologies. The Behavior Analyst, 37(1), 25-40. doi:10.1007/ s40614-014-0006-1

Morris, B. J., Croker, S., Zimmerman, C., Gill, D., \& Romig, C. (2013). Gaming science: The "gamification" of scientific thinking. Frontiers in Psychology, 4, 1-16. doi:10.3389/fpsyg.2013.00607

Mozelius, P. (2014). Game based learning - a way to stimulate intrinsic motivation. In T. Arenas Yáñez, O. Saavedra Rodriguez, \& P. Griffiths (Eds.) Proceedings of the 9th International Conference on e-Learning ICEL (pp. 272-278). Academic Conferences Publishing.

Partnership for 21st Century Skills (2015). P21 framework definitions. Retrieved from http://www.p21.org/storage/documents/ docs/P21_Framework_Definitions_New_ Logo_2015.pdf

Rientes, B., Alcott, P., \& Jindal-Snape, D. (2014). To let students self-select or not: That is the question for teachers of culturally diverse groups. Journal of Studies in International Education, 18(1), 64-83.

Ryan, R. M., \& Deci, E. L. (2000). Self-determination theory and the facilitation of intrinsic motivation, social development, and wellbeing. American Psychologist, 55(1), 6878. doi:10.1037/0003-066X.55.1.68
Saunderson, R. (2011) Making learning fun. Training, 48(6), 70-71.

Sprinthall, R. C. (2012). Basic Statistical Analysis (9th ed.). Boston, MA: Pearson Education, Inc.

Stokoe, R. (2012). Curiosity, a condition for learning. The International Schools Journal, 32(1), 63-65.

Su, C., \& Cheng, C. (2015). A mobile gamification learning system for improving the learning motivation and achievements. Journal of Computer Assisted Learning,31(3), 268-286. doi:10.1111/jcal.12088

The London School of Economic and Political Science (2010). FAQ 18: What are some good tips for phrasing questions in a survey to children? Retrieved from http://www.lse.ac.uk/ media@1se/research/EUKidsOnline/ B e s t Pract i c e Guid e/F A Q 18 . aspx\#DynamicJumpMenuManager_1_ Anchor 5

Vecchione, M., Alessandri, G., \& Marsicano, G. (2014). Academic motivation predicts educational attainment: Does gender make a difference? Learning and Individual Differences, 32, 124-131. doi:10.1016/ j.lindif.2014.01.003

Vos, N., van der Meijden, H., \& Denessen, E. (2011). Effects of constructing versus playing an educational game on student motivation and deep learning strategy use. Computers \& Education, 56(1), 127-137. doi:10.1016/j.compedu.2010.08.013

Wagner, T. (2014). The global achievement gap. New York, NY: Perseus Books Group.

Wang, H., \& Sun, C. T. (2011). Game reward systems: Gaming experiences and social meanings. In C. Marinka, K. Helen, \& W. Annika (Eds.), Proceedings of the DiGRA 2011 Conference: Think design play (pp. 1-12). 


\section{Contact the Author}

\section{Domenic Dini}

$\mathrm{PhD}$, Technology Teacher

Washoe County School District

Reno, Nevada, USA

Email: domenicdini@gmail.com

\section{Leping Liu}

Professor

Information Technology in Education

University of Nevada, Reno, USA

Email: liu@unr.edu 